\title{
Resistance to Meloidogyne enterolobii and Meloidogyne incognita in Cultivated and Wild Cowpea
}

\author{
Rocheteau Dareus \\ Agronomy Department, University of Florida, Gainesville, FL 32608
}

Antonio Carlos Mota Porto

Biology Department, Universidade Federal de Lavras, Lavras, MG, 37200000, Brazil

\section{Mesfin Bogale and Peter DiGennaro \\ Entomology and Nematology Department, University of Florida, Gainesville, FL 32611}

Carlene A. Chase

Horticultural Sciences Department, University of Florida, Gainesville, FL 32611

\author{
Esteban Fernando Rios \\ Agronomy Department, University of Florida, Gainesville, FL 32608
}

Additional index words. germplasm, root-knot nematode, legume, Vigna unguiculata

\begin{abstract}
Cowpea [Vigna unguiculata (L.) Walp] is a multipurpose crop that provides nutrients for human and livestock diets, as well as regulates and supports ecosystem services. In developing countries, cowpea is exploited as a dual-purpose crop for its grain and fodder; it is cultivated primarily for grain and as a cover crop in industrialized countries. However, root-knot nematodes (RKNs) (Meloidogyne spp.) represent a threat to cowpea production worldwide. Thus, we screened the University of California, Riverside (UC-Riverside), cowpea mini-core collection for resistance to Meloidogyne incognita Kofoid and White (Chitwood) and M. enterolobii Yang and Eisenback to verify the potential of this collection to be used for improving RKN resistance in cowpeas. Both screenings showed significant genotypic variation and medium/high broad-sense heritability $\left(H^{2}\right)$ estimates for most traits, and several traits were also strongly correlated. For the $M$. incognita screening, $86.1 \%$ of accessions showed some level of resistance based on gall score $(\leq 3)$, and $77.7 \%$ based on reproduction index $(\mathrm{RI})(25 \leq \mathrm{RI} \leq 50)$, whereas only $10.4 \%$ and $29.8 \%$ of accessions were resistant to $M$. enterolobii based on gall score $(\leq 3)$ and RI $(25 \leq \mathrm{RI} \leq 50)$, respectively. These results demonstrate the greater virulence of $M$. enterolobii than $M$. incognita in cowpea, and that geographic origin of germplasm was not linked to sources of resistance. Among cultivars, only US-1136 showed resistance against both nematode species, whereas 12 wild/landrace germplasms exhibited resistance to $M$. incognita and $M$. enterolobii, and can be exploited for breeding resistant cowpeas.
\end{abstract}

Cowpea [Vigna unguiculata (L.) Walp] is an annual legume widely grown in the tropics and subtropics for its nutritional benefits, and as an income source for small farmers in developing countries (Langyintuo et al.,

\footnotetext{
Received for publication 15 Dec. 2020. Accepted for publication 20 Jan. 2021.

Published online 25 February 2021.

This research was funded by the United States Agency for International Development under Cooperative Agreement AID-OAA-A-15-00039, Appui à la Recherche et au Développement Agricole (AREA) project, and by the USDA National Institute of Food and Agriculture, Hatch project 1018058.

E.F.R. is the corresponding author. E-mail: estebanrios@ufl.edu.

This is an open access article distributed under the CC BY-NC-ND license (https://creativecommons. org/licenses/by-nc-nd/4.0/).
}

2003; Singh, 2002, 2020). Cowpea plays a vital role as a protein source for humans, and as a feed source for livestock (Samireddypalle et al., 2017), and provides ecosystem services as a cover crop, including enhancement of soil fertility and suppression of weeds (Martins et al., 2003; Rodrigues et al., 2013). As a result of its drought and heat tolerance, cowpea holds great potential for contributing to food and feed security (Singh, 2020). Cowpea resilience and its broad range of uses rely on to the large genetic diversity found in this species (Chen et al., 2017; Huynh et al., 2013, 2018).

Major efforts have been conducted to characterizing cowpea germplasm and understanding the genetic diversity found in the species. Cowpea is a self-pollinating diploid species $(2 n=2 x=22)$, and its genome has been recently sequenced (Lonardi et al., 2019). The International Institute of Tropical
Agriculture (IITA) maintains the largest cowpea germplasm collection in the world, composed of $\approx 15,000$ cultivated and 500 wild accessions from more than 100 countries (Fatokun et al., 2018). In the United States, the largest cowpea collection of about 8000 accessions is maintained in the U.S. Department of Agriculture (USDA)Agricultural Research Service (ARS) gene bank in Griffin, GA (https://npgsweb.arsgrin.gov/). In addition, UC-Riverside maintains 6000 cultivated and wild accessions with a large genetic variation reported among 422 landraces and 46 wild accessions (Huynh et al., 2013). A molecular genetic diversity analysis of this collection revealed that the 468 accessions belong to two different gene pools: gene pool 1 is comprised of accessions from countries in West, North, and Central Africa; gene pool 2 has accessions from countries in East, Southeast, and South Africa (Huynh et al., 2013). Moreover, a mini-core collection consisting of 368 accessions was assembled, including landraces and breeding lines from 51 countries (MuñozAmatriaín et al., 2021). The mini-core was assembled based on phenotypic data, and it was also genotyped with the Cowpea iSelect Consortium Array containing 51,128 single nucleotide polymorphisms (Muñoz-Amatriaín et al., 2017). These 368 accessions were classified into six subgroups based on population structure analysis (Muñoz-Amatriaín et al., 2021). The mini-core collection has been screened for several traits, including screening for resistance to the RKN Meloidogyne incognita Kofoid and White (Chitwood) (P.A. Roberts, personal communication), and for agronomic, phenological, and morphological traits in field trials in Florida (E.F. Rios, personal communication).

Several abiotic and biotic stresses affect cowpea growth and development, impacting productivity severely (Singh and Jauhar, 2005; Timko et al., 2007). Breeding for abiotic stresses focused on heat and drought tolerance (Matsui and Singh, 2003), as well as on enhanced nitrogen fixation and tolerance to low phosphorus levels (Timko and Singh, 2008). For biotic stresses, such as RKN resistance, the IITA has released an early-maturing, high-yielding cultivar ['IT84S-2246-4' (PI 582519/UCR 437)] with resistance to $M$. incognita and $M$. javanica [Treub, 1885; Chitwood, 1949] (Ndeve et al., 2018; Roberts et al., 1996). The high-yielding cowpea cultivars CB46 and CB88 are also known to be resistant to $M$. incognita (Helms et al., 1991a, 1991b). Other cowpea breeding and selection efforts for RKNs resulted in several resistant cultivars, including the line IT89KD-288 (Ehlers et al., 2000), 'Iron Clay' (McSorley et al., 1999), and three public releases from the USDA-ARS named US-1136, US-1137, and US-1138 (Harrison et al., 2014).

Although cowpea production is profitable, environmentally friendly, and socially acceptable, RKNs pose real challenges in production systems that incorporate cowpea into their crop rotation scheme (Jones et al., 2013). RKNs affect root systems and impair 
the uptake of water and nutrients necessary for normal plant physiological functions. The RKN genus Meloidogyne is composed of about 100 species, and M. incognita is considered the most prevalent nematode species (Elling, 2013). Recently, M. enterolobii has been reported as an emerging RKN species capable of breaking resistance in several crops/cultivars known to be resistant to RKN (Brito et al., 2007, 2020; Cantu et al., 2009; Castagnone-Sereno, 2012; Cetintas et al., 2007; de Melo et al., 2011; Guilherme et al., 2016; Kiewnick et al., 2009; Singh et al., 2013). Moreover, the incidence of $M$. enterolobii has resulted in quarantines in several countries because of its virulence and aggressiveness on cultivated crops (Castagnone-Sereno, 2012; Elling, 2013; Santos et al., 2019).

The use of resistant cultivars is a suitable alternative for integrated pest management practices to address the challenges imposed by RKNs in production systems that incorporate cowpea in crop rotations as a cash or cover crop. Furthermore, the identification of novel resistant loci and inheritance mechanisms within cowpea may be broadly applicable to other agronomic crops. For this study, we hypothesized that several cowpea accessions from the UC-Riverside mini-core collection are resistant to $M$. incognita and $M$. enterolobii. The objective of this study was to screen and select cowpea accessions that exhibit resistance to $M$. incognita and $M$. enterolobii for future use in breeding for RKN resistance.

\section{Materials and Methods}

Plant material. A total of 113 cultivated and wild accessions from the UC-Riverside mini-core collection were used in three experiments: 1) 72 accessions were used in the M. incognita screening, 2) 67 accessions in the first M. enterolobii screening, and 3) 108 accessions were used in the second $M$. enterolobii screening. Previous studies revealed that 57 accessions from the UC-Riverside mini-core were resistant to $M$. incognita (all were included in the three experiments) (P.A. Roberts et al., unpublished data), and two susceptible accessions were used in this study: PI 151562 and PI 148681. In addition, other checks included PIs from the USDAGermplasm Resources Information Network (PI 115674, a resistant check), three lines released by the USDA-ARS (US-1136, US1137, and US-1138) (Harrison et al., 2014), and commercial cultivars White Acre, Black Eye, Zipper Cream, Texas Cream 40, Mississippi Silver, Mississippi Purple, and Iron Clay. The susceptible tomato cultivar BHN589 was used in the $M$. enterolobii screening experiment. The germplasms used in the screening experiments come from 27 countries (Fig. 1, Supplemental Table 1).

Nematode isolates. The Division of Plant Industry accession no. N01-514-3B collected from Redland in Miami-Dade County, FL, was used for the M. enterolobii screening and it was obtained through the Department of
Nematology and Entomology, University of Florida. The $M$. incognita inoculum was provided by the University of Florida Nematology Laboratory at the Department of Nematology and Entomology, University of Florida, and was extracted according to the method described by Hussey and Barker (1973). Briefly, soil debris was washed off the roots under running deionized water. The roots were then cut into small pieces $(\approx 2 \mathrm{~cm})$ and eggs were extracted by stirring the pieces for $5 \mathrm{~min}$ in $1.05 \% \mathrm{NaOCl}$ solution (Hussey and Barker, 1973). Eggs were separated from the root pieces by passing the suspension through a stack of sieves $(75-\mu \mathrm{m}$ sieve placed over a $25-\mu \mathrm{m}$ sieve; Gilson), and washing the eggs from the $25-\mu \mathrm{m}$ sieve into 50-mL tubes.

Nematode screening assays. The M. incognita screening experiment was carried out in growth chambers at the Agronomy Department Weed Science Laboratory, University of Florida, in Spring 2019. The methodology used for this screening was described by Atamian et al. (2012). Briefly, cowpea seeds obtained from the UCRiverside mini-core collection were surfaced-sterilized using $10 \mathrm{~mL} 95 \%$ ethanol for $2 \mathrm{~min}$, then were rinsed and placed in $0.6 \% \mathrm{NaOCl}$ for $5 \mathrm{~min}$, rinsed again with sterile water, and one seed per accession was sown in the top of a growth pouch $(17 \times 16$ $\mathrm{cm}$ ) (HC Blue Blotter seed germination pouch, CYG TM). The pouches were placed vertically in a rack inside a growth chamber (Seed Germination Chamber, Percival) kept at $28^{\circ} \mathrm{C} / 25^{\circ} \mathrm{C}$ in a 16 -h light $/ 8$-h dark cycle. Two weeks after germination, each seedling was inoculated with $250 \mathrm{M}$. incognita second-stage infective juveniles, distributed evenly around the stem at a distance of $\approx 1$ $\mathrm{cm}$ from the base of the plant. Commercial cultivars Iron Clay and Texas Cream 40, and USDA germplasm line US-1136 were screened as negative controls in the experiment. Plants were watered once or twice a day with half-strength Hoagland's solution (Hoagland Modified Basal Salt Mixture; Phyotechnology Laboratories, KS: H353) for 8 weeks after inoculation to keep the roots moist, and to avoid saturating the pouch with excess solution. The pouches were set up in a randomized complete block design (RCBD) with four replicates in two growth chambers, using the growth chambers as the blocking component. A single seed from each genotype was sown in each pouch.

The M. enterolobii experiments were conducted in the Forage Breeding and Genetics Laboratory, Agronomy Department, University of Florida. One seedling per accession was sown in cone-tainers (height, $20 \mathrm{~cm}$; diameter, $4 \mathrm{~cm}$ ) filled with sterilized sandy soil (Quikrete Premium Play Sand; Quikrete). Two weeks after germination, seedlings were inoculated with $250 \mathrm{M}$. enterolobii second-stage infective juveniles using a calibrated pipette. The plants were either watered or fertilized using Scotts 10-10-10 $\left(\mathrm{N}-\mathrm{P}_{2} \mathrm{O}_{5}-\mathrm{K}_{2} \mathrm{O}\right)$ granular fertilizer diluted before application. Experimental units were set up as an RCBD with four replications. The M. enterolobii screening was repeated in Spring 2020 using 108 accessions, with an RCBD with two replications.

Data collection. The same data collection procedure was used in all experiments. Eight weeks after inoculation, roots were rated visually for galling response using the 0 - to 5-point gall index, with $0=$ immune, $1=$ highly resistant, 2 = resistant, $3=$ moderately resistant, $4=$ moderately susceptible to susceptible, and $5=$ highly susceptible (Taylor and Sasser, 1978). Root fresh biomass (measured in grams) was recorded before immersion in $\mathrm{NaOCl}$ to extract nematode eggs. Eggs were collected and counted using a stereomicroscope, and the number of eggs per gram of cowpea roots was calculated. The RI was calculated as follows to assess the degree of resistance or susceptibility of each genotype:

$\mathrm{RI}=$

No.of eggs/gram of root

No.of eggs/gram of susceptible control roots $\times 100$.

Plants were rated for $\mathrm{RI}$ as follows: $\mathrm{RI}=0$, immune; RI $<1$, highly resistant; $1 \leq \mathrm{RI}<$ 10 , very resistant; $10 \leq \mathrm{RI}<25$, moderately resistant; $25 \leq \mathrm{RI}<50$, slightly resistant; and RI $\geq 50$, susceptible (Taylor, 1967; Karuri et al., 2017). In the second $M$. enterolobii screening, only gall index and root fresh weight were measured because of the lack of access to laboratories during the COVID19 shutdown.

Statistical analyses. Data were analyzed using linear mixed models in ASReml-R v.4 (Butler et al., 2017), which provides variance component estimates using the residual maximum likelihood. Likelihood radio tests were implemented to verify the significance of random effects (Gilmour et al., 1995). Checks for outliers and of the model assumptions were accomplished using diagnostic plots within ASReml-R. For each trait and each experiment, analyses were performed using the model

$$
\boldsymbol{y}=\boldsymbol{X}_{1} \mu+\boldsymbol{X}_{2} \boldsymbol{b}+\boldsymbol{Z}_{1} \boldsymbol{g}+\boldsymbol{e},
$$

where, $\boldsymbol{y}$ is the vector of phenotypic values; $\boldsymbol{X}$ and $\boldsymbol{Z}$ represent the incidence matrices for fixed and random effects, respectively; $\mu$ is the overall mean; $\boldsymbol{b}$ is the vector of block; $\boldsymbol{y}$ is the vector of year; $\boldsymbol{g}$ is the vector genotypes with $\approx M V N\left(0, \sigma_{g}^{2} \boldsymbol{I}\right)$ where $M V N$ is multi-variante normal distribution; and $\boldsymbol{e}$ is the random vector residual with $\boldsymbol{e} \approx M V N\left(0, \sigma_{e}^{2} \otimes \boldsymbol{I}\right)$. For each trait and multiyear, analyses were performed using the model

$$
\boldsymbol{y}=\boldsymbol{X}_{1} \boldsymbol{\mu}+\boldsymbol{X}_{2} \boldsymbol{b}+\boldsymbol{X}_{2} \boldsymbol{y}+\boldsymbol{Z}_{1} \boldsymbol{g}+\boldsymbol{Z}_{2} \boldsymbol{g} \boldsymbol{y}+\boldsymbol{e},
$$

where $\boldsymbol{y}$ is the vector of phenotypic values; $\boldsymbol{X}$ and $\boldsymbol{Z}$ represent the incidence matrices for fixed and random effects, respectively; $\mu$ is the overall mean; $\boldsymbol{b}$ is the vector of block; $\boldsymbol{y}$ is the vector of year; $\boldsymbol{g}$ is the vector genotypes with $\approx \operatorname{MVN}\left(0, \sigma_{g}^{2} \boldsymbol{I}\right) ; \boldsymbol{g} \boldsymbol{y}$ is the vector genotypes-by-year interaction, with $\boldsymbol{g l} \approx$ 


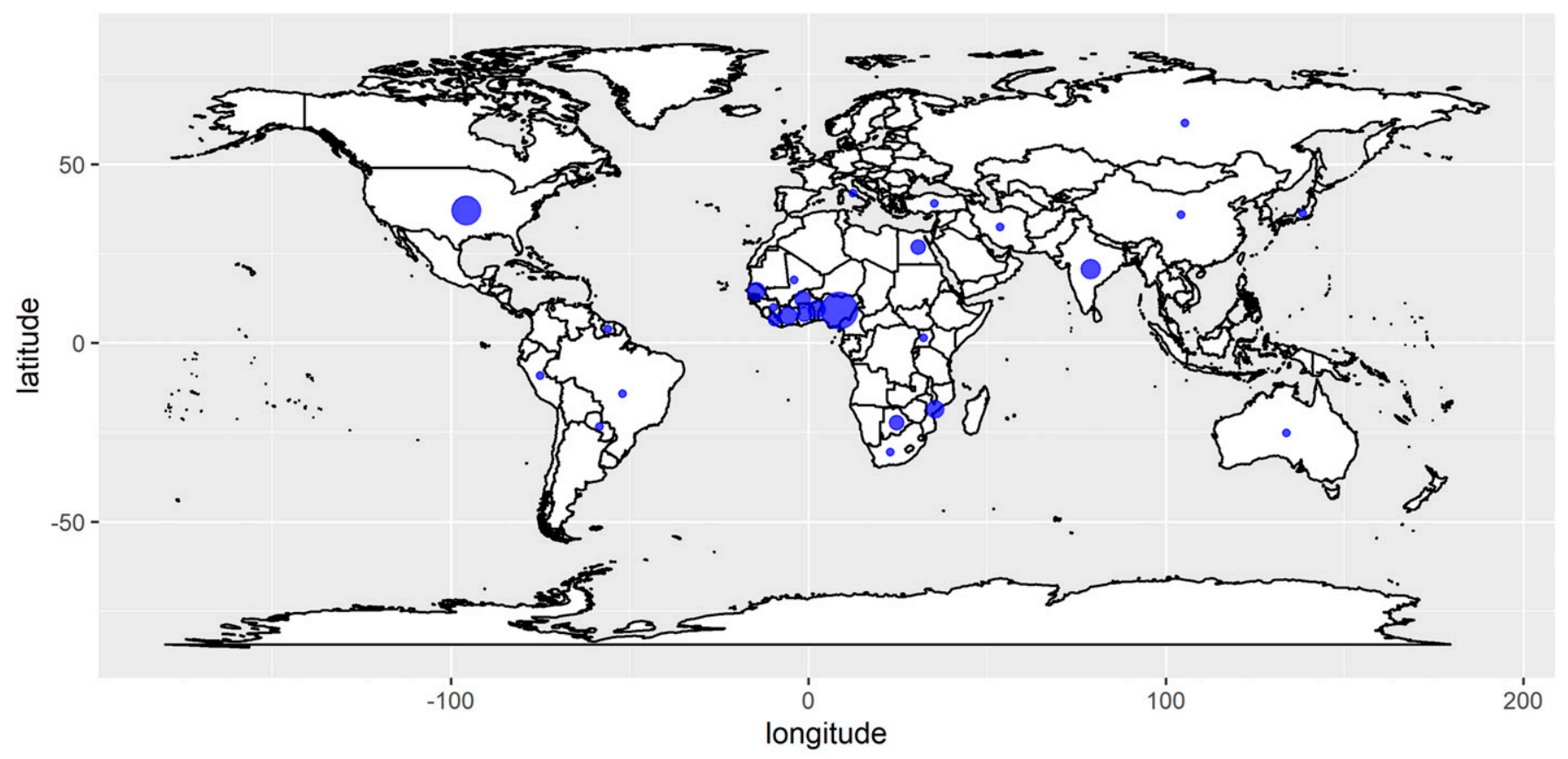

\# Genotypes $10 \bigcirc 20 \bigcirc 30$

Fig. 1. Geographic origin of the cowpea accessions evaluated in this study. The blue dots represent the latitude and longitude coordinates of collection sites, and the size of the dot is proportional to the number of accessions collected from that location.

$\operatorname{MVN}\left(0, \otimes \sigma_{g y}^{2} \boldsymbol{I}\right) ;$ and $\boldsymbol{e}_{i}$ is the random vector for the $i$ th years 1 and 2 , with $\boldsymbol{e}_{1} \approx M V N(0$, $\left.\sigma_{e 1}^{2} \otimes \boldsymbol{I}\right)$ and $\boldsymbol{e}_{2} \approx M V N\left(0, \sigma_{e 2}^{2} \otimes \boldsymbol{I}\right)$.

When residuals did not meet the assumptions for Gaussian distribution, response variables were transformed using the Box-Cox procedure with the following equation:

$$
y_{t}(\lambda)=\left\{\begin{array}{cc}
\frac{y^{\lambda}-1}{\lambda}, & \text { if } \mid x<0 \\
\log y, & \text { if } \mid x \geq 0
\end{array}\right.
$$

where $\lambda$ is the parameter that defines the transformation, $y$ is the variable, and $y_{t}$ is the transformed data. Here, the lambda value estimation $(\lambda)$ was based in the likelihood maximization method (Box and Cox, 1964) of the model adjusted for each variable, treating factors in the model as fixed. For this, the boxcox function of the MASS package was implemented in R (Ripley et al., 2020).

For each trait, the predicted genotypic values were used to rank accessions and to calculate genetic correlations among traits. The correlations were tested by a nonparametric bootstrap test with 1000 permutations at $5 \%$ probability. The predicted values were also used to generate principal component analysis (PCA) biplots in R. Other genetic and statistical parameters were calculated using the following estimators:

Broad-sense genetic heritability:

$$
H^{2}=\frac{\sigma_{g}^{2}}{\sigma_{g}^{2}+\frac{\sigma_{e}^{2}}{r}}
$$

Multiexperiment broad-sense genetic heritability:
$H^{2}=\frac{\sigma_{g}^{2}}{\sigma_{g}^{2}+\frac{\sigma_{g y}^{2}}{b}+\frac{\left(\frac{\sigma_{e 1}^{2}}{r 1}+\frac{\sigma_{e 2}^{2}}{r 2}\right)}{2}}$

Type B correlation between experiments:

$r_{g B}=\frac{\sigma_{g}^{2}}{\sigma_{g}^{2}+\sigma_{g y}^{2}}$

Coefficient of genetic variation:

$C V_{g}=\frac{\sqrt{\sigma_{g}^{2}}}{\bar{X}}$

Coefficient of environmental variation:

$\frac{C V_{e}=\sqrt{\overline{\sigma_{g}^{2}}}}{\bar{X}}$

Relative coefficient of variation:

$C V_{r}=\frac{C V_{g}}{C V_{e}}$

\section{Results}

M. incognita screening. All traits exhibited highly significant $(P<0.01)$ genetic variances, and $H^{2}$ varied from 0.78 to 0.92 (Table 1). All traits, except for fresh root biomass, exhibited genetic variances larger than residual variances (Table 1). Nematode eggs were not found in $35 \%$ of the accessions and, consequently, eggs per gram of root and RI presented a range with a minimum of 0 (immune to $M$. incognita). Also, the ranking of accessions for number of eggs, eggs per gram g of root, and RI were similar, whereas significant changes in ranking were observed for gall score and root fresh weight (Fig. 2A). Accessions from Europe, South Africa, and West Africa showed greater resistance to $M$. incognita than accessions from Asia and Oceania (Fig. 2C).

Gall score varied from 0.5 to 3.75 (Table 1), and 53 accessions showed some level of resistance to $M$. incognita (30 highly resistant, 13 resistant, and 10 moderately resistant) and 14 were susceptible (moderately susceptible to susceptible) (Fig. 2D). All commercial cultivars as well as PI 115674, US-1136, US-1137, and US1138 were resistant to $M$. incognita based on gall score (Fig. 2A, Supplemental Table 2). Twenty-five genotypes (23 accessions, US-1138, and 'Zipper Pea') were found to be immune to $M$. incognita because their RI was equal to zero (Fig. 2D, Supplemental Table 2). Based on RI, seven genotypes (five accessions, Iron Clay, and US-1136) were highly resistant; 10 genotypes (five accessions, 'Mississippi Silver', 'Mississippi Purple', US-1137, and PI 115674) were very resistant. Fourteen genotypes (12 accessions, 'Black Eye', and PI 148681) were moderately resistant, and four accessions were slightly resistant to $M$. incognita. Twelve genotypes (nine accessions, 'Texas Cream 40', 'White Acre', and PI 151562) were found to be susceptible to $M$. incognita (Fig. 2D, Supplemental Table 2).

$\mathrm{M}$. enterolobii screening. Large genetic variability was found among cowpea genotypes used in this study (Fig. 3, Table 2). All traits exhibited highly significant $(P<0.01)$ genetic variances, and $H^{2}$ varied from 0.50 to 
Table 1. Estimates of variance components for five traits measured on 59 cowpea accessions from the University of California, Riverside, mini-core collection and 13 cultivars infected with Meloidogyne incognita.

\begin{tabular}{|c|c|c|c|c|c|}
\hline Parameter & No. of eggs & Eggs/g root & Root biomass (g) & Reproduction index & Gall score \\
\hline$H^{2}$ & $0.86(0.02)$ & $0.92(0.01)$ & $0.78(0.04)$ & $0.86(0.03)$ & $0.89(0.02)$ \\
\hline$C V_{g}$ & 1.63 & 1.85 & 0.41 & 3.94 & 0.50 \\
\hline$C V_{r}$ & 1.79 & 1.74 & 0.95 & 1.73 & 1.47 \\
\hline $\bar{X}^{\mathrm{a}}$ & $3,642.91$ & $1,217.19$ & 2.67 & 19.00 & 1.81 \\
\hline Range $^{z}$ & $0.00-42,058.75$ & $0.00-12,412.04$ & $0.43-5.71$ & $0.00-133.03$ & $0.50-3.75$ \\
\hline
\end{tabular}

${ }^{\mathrm{z}}$ Mean values reported after back-transforming response variables.

$\sigma_{g}^{2}=$ variance among genotypes, $\sigma_{e}^{2}=$ residual variance; $H^{2}=$ broad-sense genetic repeatability; $C V_{g}=$ coefficient of genetic variation; $C V_{e}=$ coefficient of environmental variation; $C V_{r}=$ relative coefficient of variation; $\bar{X}=$ overall mean across all accessions.

**Significant by the likelihood ratio test at $1 \%$ probability.

A Ranking interaction among traits

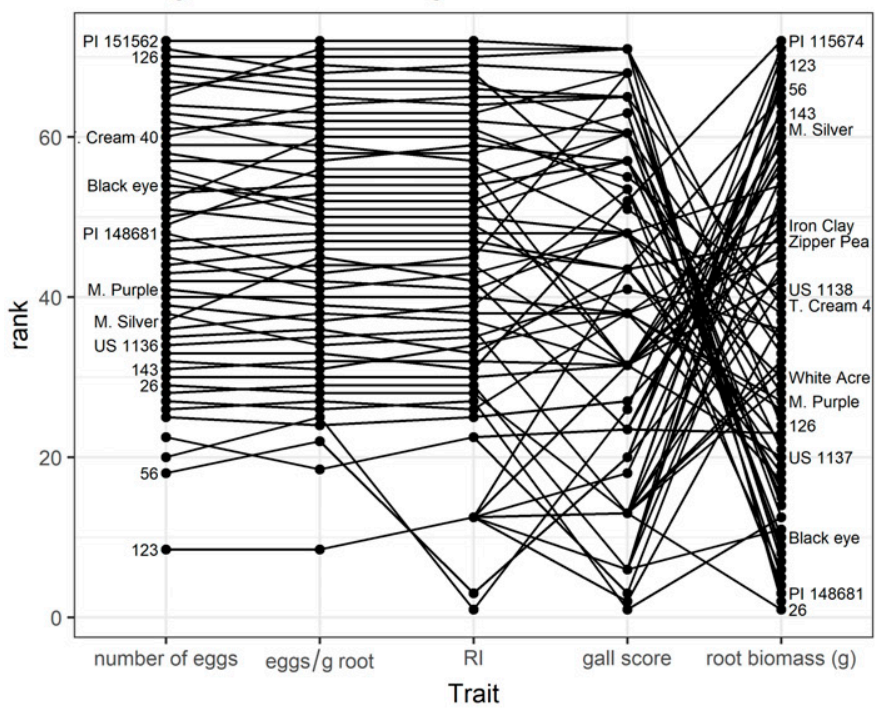

B

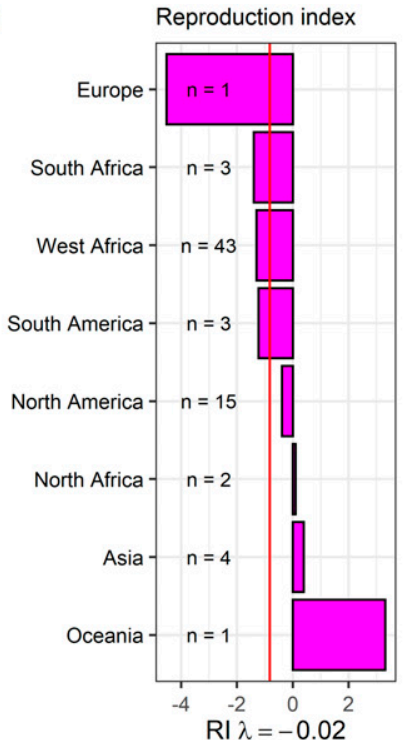

C

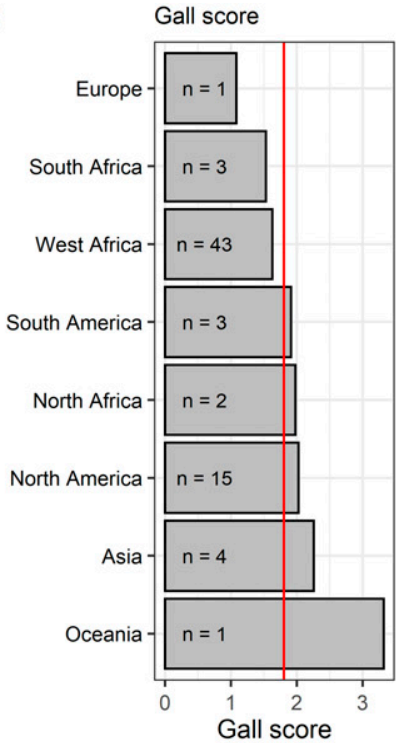

D Mean of Reproduction Index of cowpea accessions

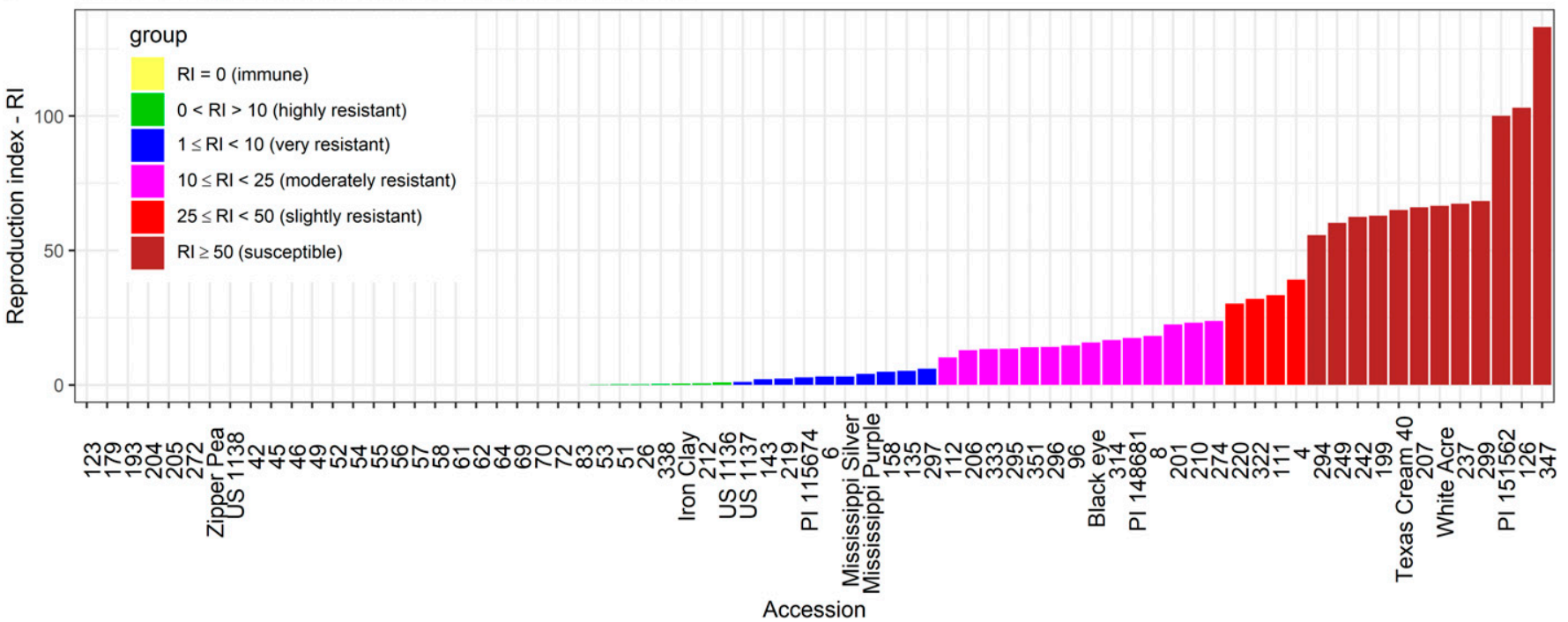

Fig. 2. Response of 59 cowpea accessions from the University of California, Riverside, mini-core collection and 13 commercial cultivars infected with Meloidogyne incognita screened in 2019. (A) Ranking of accessions across five traits. (B) Mean of predicted values of cowpea accessions by region of origin for reproduction index (RI) (red line, overall mean). (C) Mean of predicted values of cowpea accessions by region of origin for gall score (red line, overall mean). (D) Resistance level based on RI across accessions.

0.72 at single analysis, whereas $H^{2}$ estimates were 0.44 for root biomass and 0.48 for gall score for the combined analysis for both years (Table 2). The results also demonstrate that the variables related to the number of galls and eggs had greater residual variation than genetic variation, with $C V_{r}$ ranging between 0.50 and 0.81 (Table 2).
Based on gall score, eight genotypes were considered resistant, 34 were moderately resistant (including 'Iron Clay', 'Mississippi' Silver', 'Mississippi Purple', 'Texas Cream 
40', 'Zipper Pea') (Supplemental Table 3). Twenty-two genotypes were moderately susceptible to susceptible, including the USDA germplasm lines US-1137 and US1138, and the cultivar Black Eye (Supplemental Table 3). For the analysis combining screenings performed in both years, accession 126 exhibited high susceptibility and accession 193 was highly resistant based on gall index measured in both years (Supplemental Table 3), and the level of resistance across accessions screened in the 2-year analysis showed high repeatability for gall score $\left(r_{g B}=0.95\right)$ (Table 2).

RIs calculated for the $M$. enterolobii screening varied from very resistant to susceptible, and $76 \%$ of genotypes were considered susceptible (Fig. 3D, Supplemental Table 3). Four accessions were classified as very resistant; three others were moderately resistant (Fig. 3D). Eight genotypes were slightly resistant to $M$. enterolobii $(25 \leq \mathrm{RI}$ $<50$ ), including US-1136. The remaining 53 genotypes were all susceptible, including six commercial cultivars (Iron Clay, Mississippi Silver, Mississippi Purple, Zipper Pea, Black Eye, and Texas Cream 40) and the USDA germplasm lines US-1137 and US-1138 (Fig. 3D, Supplemental Table 3).

Principal component analysis. The biplot for $M$. incognita showed that the first two components (PCA1 and PCA2) accounted for $95 \%$ of the variation for the response to $M$. incognita inoculation across the five traits (Fig. 4A). The first component (PCA1) explained $83 \%$ of the variation, with gall score, number of eggs, number of eggs per gram of root, and RI contributing more toward the variation in the first component. The second component (PCA2) explained $12 \%$ of the variation, and fresh root biomass contributed more toward PCA2. No distinct clustering was observed for accessions, particularly regarding their region of origin. Several accessions from West Africa and North America presented high levels of susceptibility and resistance.

Both $M$. incognita-susceptible and -resistant accessions produced low and high root biomass, indicating a lack of relationship between root biomass and resistance level (Fig. 4A). The PCA biplot and the correlogram highlight moderate to high correlations among traits (Fig. 4A, Supplemental Fig. 1A). All traits correlated positively, and very high correlations were found between egg count, number of eggs per gram of root, and RI (Fig. 4A, Supplemental Fig. 1A).

The biplot for $M$. enterolobii showed that the first two components (PCA1 and PCA2) accounted for $92 \%$ of the variation for the response to $M$. enterolobii inoculation across the five traits (Fig. 4B). PCA1 explained $71 \%$ of the variation, with gall score, number of eggs, number of eggs per gram of root, and RI contributing more toward the variation in the first component. PCA 2 explained $21 \%$ of the variation, and fresh root biomass contributed more toward PCA2. There was not a clear clustering of accessions based on their region of origin. Thus, accessions with a high level of resistance and high levels of susceptibility were found within the same region of origin.

The biplot and the correlogram showed low to high positive correlations among traits for M. enterolobii (Fig. 4B, Supplemental Fig. 1B). Very high correlations were found between egg count, number of eggs per gram of root, RI and gall score; low correlation coefficients were estimated between all traits and root biomass, except for a moderate correlation with number of eggs (Fig. 4B, Supplemental Fig. 1B). Moderate correlation coefficients $(P<0.05)$ were obtained for number of eggs per gram of root, RI, and gall score between the predicted values estimated using the 63 genotypes screened in both trials ( $M$. incognita and $M$. enterolobii). However, the correlation between predicted values estimated using the 63 genotypes screened in both trials was nonsignificant $(P>0.05)$ for root biomass (Supplemental Fig. 1C)

\section{Discussion}

Germplasms tested in all RKN screening experiments were genetically diverse for all traits. Genotypic variances and estimated $H^{2}$ for the $M$. incognita screening experiment were high for all traits, whereas they were medium in the $M$. enterolobii screening experiment (Tables 1 and 2). All accessions, except five genotypes, were used in both experiments in 2019, and most of the genotypes were more heavily galled, had more eggs, and resulted in greater RIs for $M$. enterolobii than for M. incognita. In addition, the germplasms exhibited greater genetic variability for $M$. incognita $\left(C V_{r}>1\right)$ than for M. enterolobii $\left(C V_{r}<1\right)$ (Tables 1 and 2). These results may indicate different pathogen-host interactions between the two nematode species. For $M$. incognita, the $R k$ locus in cowpea has been used extensively to breed RKN-resistant varieties in the United States and other countries, and this locus confers resistance to many populations of M. incognita, M. arenaria, M. hapla, and $M$. javanica (Das et al., 2008, Huynh et al., 2016; Roberts et al., 1996). That is, RKN inheritance for $M$. incognita resistance in cowpea is controlled by a few major quantitative trait loci (QTLs)/genes, resulting in less environmental influence in phenotypic expression and greater heritability estimates. However, there are no reports available in the literature about inheritance of cowpea resistance to $M$. enterolobii. Our study results indicate that the resistance level of $M$. enterolobii might be more polygenic than $M$. incognita, causing lower heritability estimates and a fewer number of genotypes presenting high resistance levels. However, future studies using breeding populations should confirm the hypothesis for polygenic inheritance in $M$. enterolobii.

In the M. incognita screening experiment, 53 UC-Riverside mini-core accessions showed resistance to $M$. incognita, out of 
A Ranking interaction among traits

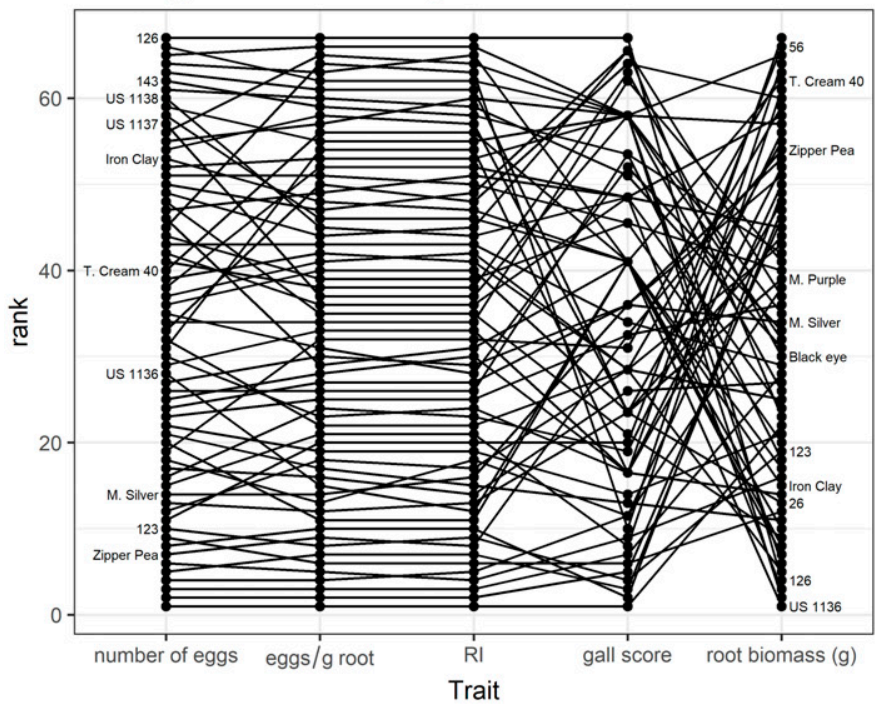

B

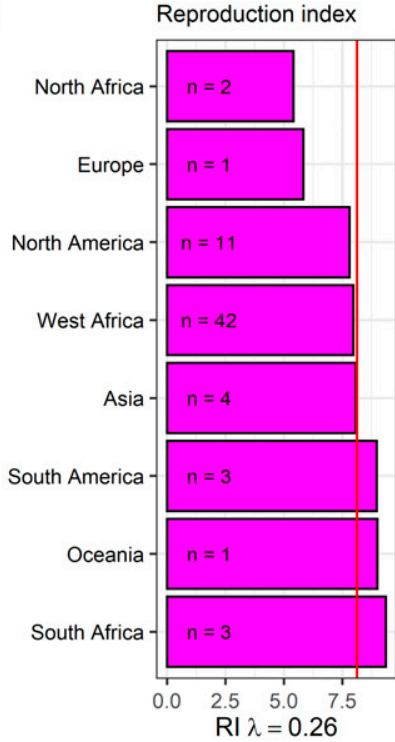

C

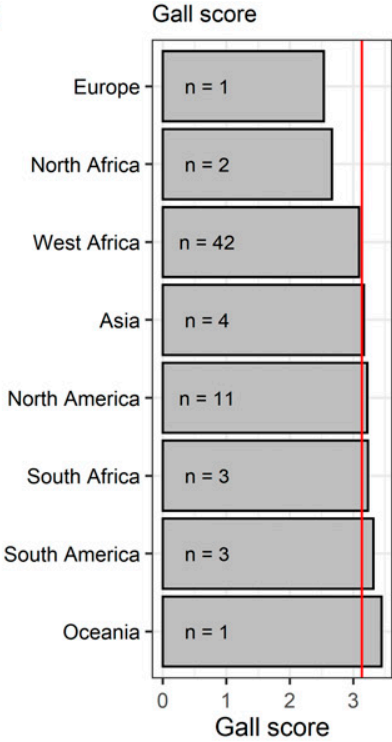

D Mean of the Reproduction index of cowpea accessions

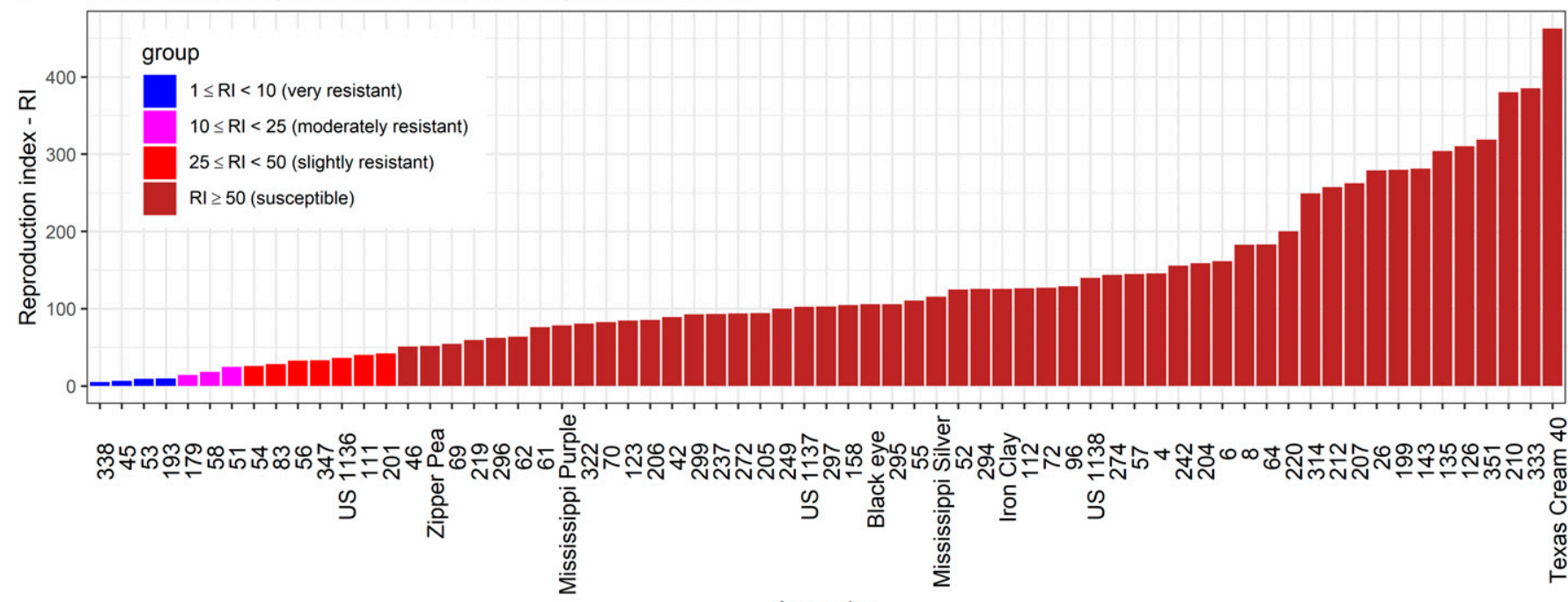

Accession

Fig. 3. Response of 58 cowpea accessions from the University of California, Riverside, mini-core collection and 9 commercial cultivars infected with Meloidogyne enterolobii screened in 2019. (A) Ranking of accessions across five traits evaluated. (B) Mean of predicted values of cowpea genotypes by region of origin for reproduction index (RI) (red line, overall mean). (C) Mean of predicted values of cowpea genotypes by region of origin for gall score (red line, overall mean). (D) Resistance level based on RI across accessions.

the 56 accessions known to be $M$. incognita resistant based on previous screenings (P.A. Roberts et al., unpublished data). The three USDA germplasm lines (US-1136, US-1137, and US-1138) and the cultivars Mississippi Silver, Mississippi Purple, Iron Clay, and Zipper Pea exhibited high levels of resistance to $M$. incognita because they have been selected for RKN resistance (Fery, 2009; Harrison et al., 2014; Swanson and Van Gundy, 1984). These results suggest that these germplasm lines and cultivars may carry the same resistant, single dominant $R k$ gene, which is effective against three RKN species (M. incognita, M. javanica, and $M$. hapla) (Fery and Dukes 1980; Huynh et al., 2016; Roberts et al., 1996). The gall scores for US-1136, US-1137, US-1138, and 'Mississippi Silver' are similar to the values previously reported by Harrison et al.
(2014), whose reported gall score values ranged from 1.4 to 1.7. Despite the germplasm lines showing similar levels of resistance in the two studies, total numbers of eggs were very different. In our study, total number of eggs for these four genotypes varied from 0 to 258 eggs per plant, whereas Harrison et al. (2014) reported 2644 to 7622 eggs per plant. This discrepancy could be explained by the different germplasm used in both studies, and also because of different screening methods [growth pouches in our study, greenhouse pot study by Harrison et al. (2014)]. US-1138, 'Zipper Pea', and 23 RKN-resistant accessions (P.A. Roberts et al., unpublished data), had an RI equal to zero (immune) - meaning, no eggs were found even though the plants' root systems had some galls in the $M$. incognita screening (gall score range, 0.5-2.5). In this scenario,
$R k$ resistance was probably involved in preventing the $M$. incognita females from developing and reproducing, rather than blocking root penetration by second-stage infective juveniles (Das et al., 2008).

In the 2-year screening for M. enterolobii, accessions with high resistance and high susceptibility were found, and genotypes exhibited similar responses in both years, given by the high correlation for gall score in the combined analysis $\left(r_{g B}=0.95\right)$ (Table 2). However, some genotypes exhibited slightly different responses to gall score in both years. These results confirm the findings of other studies supporting the tendency for $M$. enterolobii to break resistance in known RKN-resistant crop cultivars (Brito et al., 2007; Cantu et al., 2009; CastagnoneSereno 2012; Cetintas et al., 2007; de Melo et al., 2011; Guilherme et al., 2016; Kiewnick 


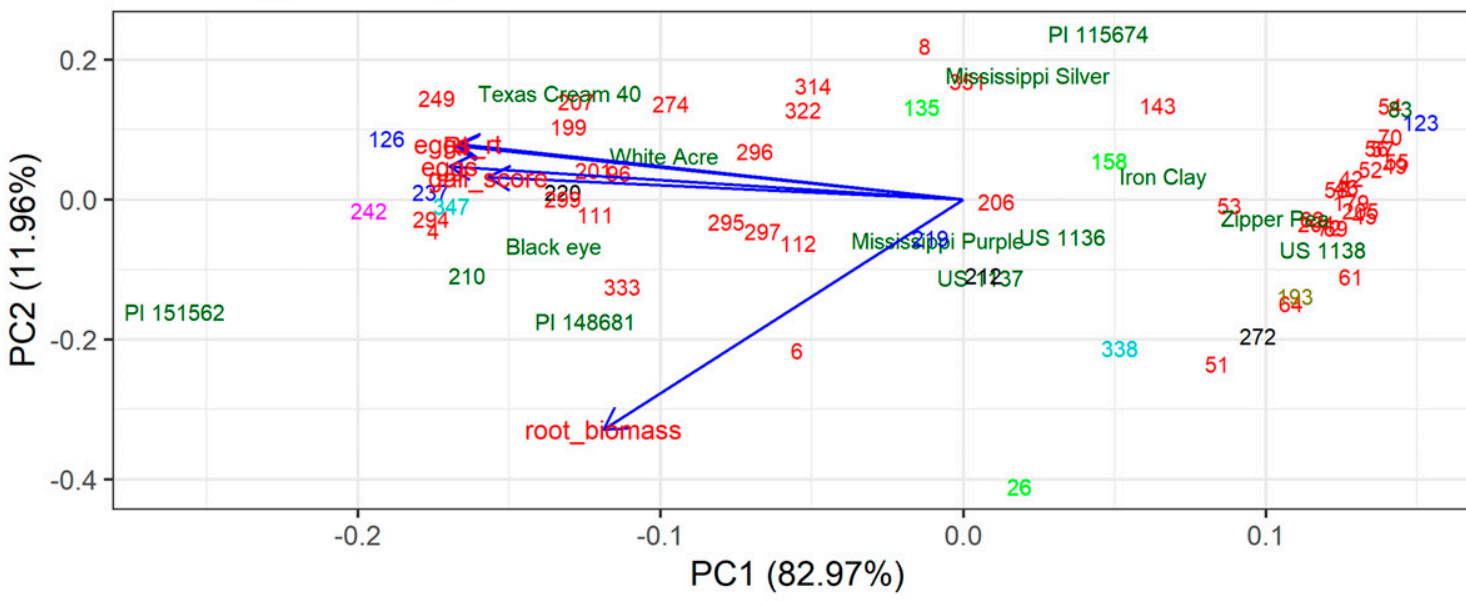

\section{Region \\ West Africa \\ - Asia \\ South Africa \\ - Europe}

\section{B Meloidogyne enterolobii}

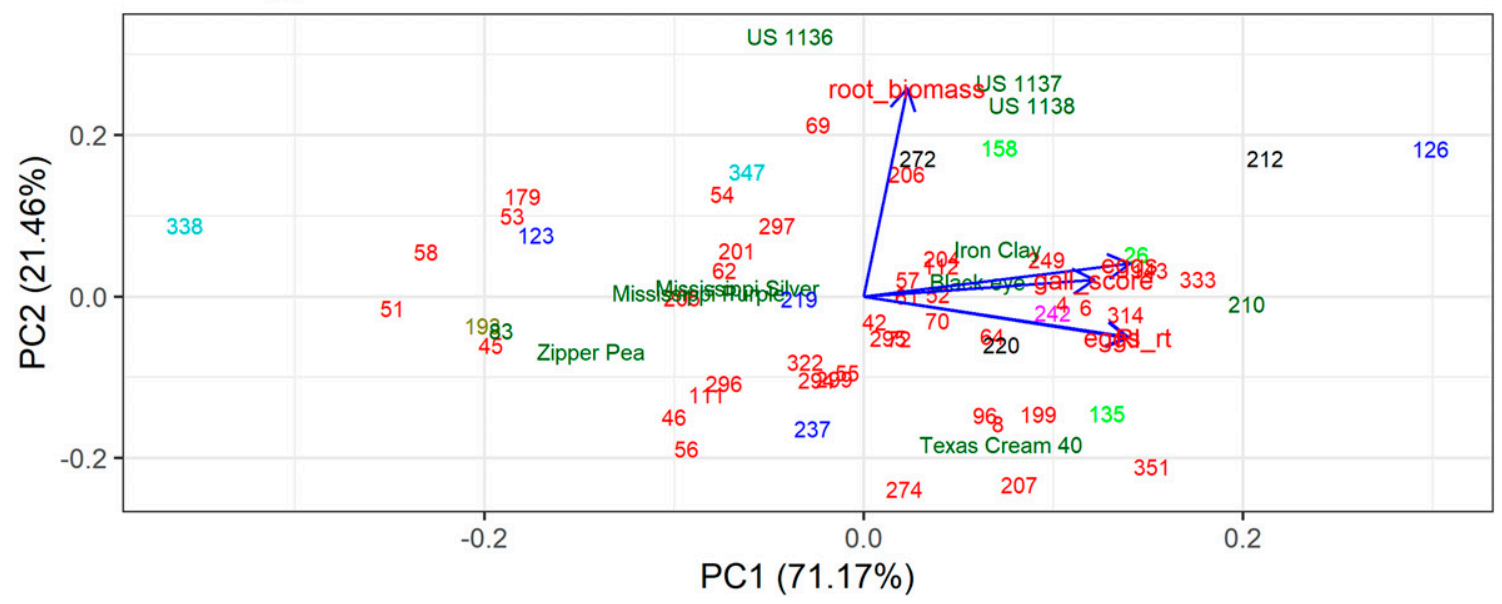

- North America

- South America

- Oceania

- North Africa

Fig. 4. Principal component analysis (PCA) of four traits using predicted values in the first year of evaluation. (A) PCA biplot for Meloidogyne incognito screening. (B) PCA biplot for Meloidogyne enterolobii screening. Traits: gall_score = gall score; eggs = number of eggs; eggs_rt = eggs per gram of root; RI = reproduction index; root_biomass $=$ root fresh weight. $\mathrm{PC} 1=$ principal component $1 ; \mathrm{PC} 2=$ principal component 2.

et al., 2009; Santos et al., 2019; Singh et al., 2013; Westerich et al., 2011).

All the cultivars/germplasm releases, except for US-1136, exhibited high susceptibility to M. enterolobii based on RI measured in 2019. Current cultivars/germplasm lines were not selected for resistance to $M$. enterolobii because most cowpea breeding programs aim at resistance to $M$. incognita and M. javanica (Ehlers et al., 2000; Helms et al., 1991a, 1991b). Although M. enterolobii is considered a polyphagous species with a high rate of reproduction and virulence across plant species, little is known about its infection behavior in legumes, and there is no previous report on screening cowpea for $M$. enterolobii. Thus, this work provides a baseline for future genetic efforts to elucidate the genetic control of $M$. enterolobii resistance in cowpea, as well as providing sources of variation to breed M. enterolobii-resistant cultivars. Moreover, $M$. enterolobii is considered a species with low intraspecific genetic variability among isolates (Tigano et al., 2010), which is advantageous for breeding programs.

There was no association between geographic origin and resistance level among accessions (Fig. 4). That is, within the same region of origin, there is variability in the level of resistance for both $M$. incognita and M. enterolobii. For example, accessions from North America showed a whole spectrum of response to both screenings (highly resistant to highly susceptible). In the same way, the resistance levels for $M$. incognita and $M$. enterolobii were unaffected by root biomass. In this regard, accessions 338 (resistant) and 126 (susceptible) had similar root biomass production and a very different response to M. enterolobii (Fig. 4B), and accessions 53 and 56 were both resistant to $M$. enterolobii but had different root biomass production (Fig. 4B).

High positive correlations were found between most pairs of resistance traits in the $M$. incognita screening (Supplemental Fig. 1A and B, Fig. 4A and B). Traits with high genetic correlations and high heritability estimates are useful for breeding purposes. Phenotyping of one trait can allow the estimation of genotypic values for another trait if both traits are highly correlated, resulting in less resources and time to phenotype large breeding populations. Hence, because total number of eggs and number of eggs per gram of root are highly correlated to RI, selection could be made for RI using either total number of eggs or number of eggs per gram of root. In the $M$. enterolobii screening, the low negative correlation between root biomass and the other traits suggests that an increase in root biomass leads to a decrease of the nematode reproduction factors.

Despite differences in methodology used in both screenings, several accessions were classified as resistant and susceptible for both nematode species for data collected in 2019 (Table 3). Accessions 123 (TVu-12897), 179 (TVu-15636), and 193 (TVu-16220) were classified among the most resistant accessions for both species using RI and gall score traits. This result shows the potential of these accessions to be exploited as sources of resistance for breeding programs targeting both nematode species. Similarly, accessions 126 (TVu-12968), 210 (TVu-1715, PI 579683), and 242 (TVu-3652, PI 579985) showed high susceptibility to both nematode species for RI and gall score. Accession 126 (TVu-12968) showed high susceptibility for both species consistently, and thus it can be 
Table 3. Resistant and susceptible accessions to Meloidogyne enterolobii and $M$. incognita based on reproduction index and gall score.

\begin{tabular}{|c|c|c|c|c|c|}
\hline \multicolumn{3}{|c|}{ Reproduction index } & \multicolumn{3}{|c|}{ Gall Score } \\
\hline UCR accession & UCR Name & Origin & UCR accession & UCR name & Origin \\
\hline \multicolumn{6}{|l|}{ Resistant } \\
\hline 123 & TVu-12897 & India & 123 & TVu-12897 & India \\
\hline 179 & TVu-15636 & Nigeria & 179 & TVu-15636 & Nigeria \\
\hline 193 & TVu-16220 & Italy & 193 & TVu-16220 & Italy \\
\hline 45 & IT84S-2049_4931 & Nigeria & 205 & TVu-16504 & Nigeria \\
\hline 54 & IT95K-1479 & Nigeria & 338 & TVu-9474 & Egypt \\
\hline 58 & IT97K-207-15 & Nigeria & 45 & IT84S-2049_4931 & Nigeria \\
\hline 83 & Lyg_321-2 & United States & 51 & IT93K-503-1_4937 & Nigeria \\
\hline \multicolumn{6}{|l|}{ Susceptible } \\
\hline 126 & TVu-12968 & India & 126 & TVu-12968 & India \\
\hline 199 & TVu-16368 & Benin & 210 & TVu-1715 & United States \\
\hline 207 & TVu-16521 & Guinea & 242 & TVu-3652 & Australia \\
\hline 210 & TVu-1715 & United States & 249 & TVu-3947 & Nigeria \\
\hline 242 & TVu-3652 & Australia & 396 & Black eye & United States \\
\hline 274 & TVu-6641 & Liberia & 4 & $58-53$ & Senegal \\
\hline 314 & TVu-8671 & Benin & & & \\
\hline 391 & Texas Cream 40 & United States & & & \\
\hline
\end{tabular}

used as a susceptible check and parental line for crosses for mapping QTLs in segregating populations. Among commercial cultivars/ germplasm releases, 'Zipper Pea' and US1136 showed high resistance levels to both nematode species, whereas 'Texas Cream 40' and 'Black Eye' had high susceptibility.

\section{Conclusions}

Genetic variability for RKN resistance to M. incognita and M. enterolobii exists within UC-Riverside's germplasm collection, and these germplasms can be used in breeding programs. Based on RI at $M$. incognita screening, $58.3 \%$ of the accessions were considered to be very resistant to immune, including some commercial cultivars such as Zipper Pea and Iron Clay, and USDA releases US-1138, US-1136, and US-1137. For $M$. enterolobii, only four accessions $(6.5 \%)$ were considered to be very resistant: 338 (TVu9474), 45 (IT84S-2049_4931), 53 (IT95K1105-5), and 193 (TVu-16220). US-1136 and 'Zipper Pea' were the genotypes with the best performance against both nematode species. Although there can be a difference between the average level of resistance based on the region of origin, the origin of germplasm in this study was not linked to sources of resistance to M. incognita and M. enterolobii. Many accessions from the UC-Riverside mini-core showed potential to be introduced into breeding programs with the goal of increasing resistance to both nematode species. However, there is a need to understand more fully the resistance mechanisms for Meloidogyne species in cowpea, especially for M. enterolobii.

\section{Literature Cited}

Atamian, H.S., P.A. Roberts, and I. Kaloshian. 2012. High and low throughput screens with root-knot nematodes Meloidogyne spp. J. Vis. Exp. 61:E3629.

Box, G.E. and D.R. Cox. 1964. An analysis of transformations. Journal of the Royal Statistical Society: Series B (Methodological) 26(2):211243.
Brito, J.A., J. Desaeger, and D.W. Dickson. 2020. Reproduction of Meloidogyne enterolobii on selected root-knot nematode resistant sweetpotato (Ipomoea batatas) cultivars. J. Nematol. 52:2020-2063.

Brito, J.A.B., J.D. Stanley, M.L. Mendes, R. Cetintas, and D.W. Dickson. 2007. Host status of selected cultivated plants to Meloidogyne mayaguensis in Florida. Nematropica 37:6471.

Butler, D.G., B.R. Cullis, A.R. Gilmour, B.J. Gogel, and R. Thompson. 2017. ASReml-R reference manual version 4. VSN International Ltd., Hemel Hempstead, UK.

Cantu, R.R., S.R.S. Wilcken, J.M.O. Rosa, and R. Goto. 2009. Reaction of commercial tomato rootstocks plant to Meloidogyne mayaguensis. Summa Phytopathol. 35:216-218.

Castagnone-Sereno, P. 2012. Meloidogyne enterolobii $(=$ M. mayaguensis): Profile of an emerging, highly pathogenic, root-knot nematode species. Nematology 14:133-138.

Cetintas, R., R. Kaur, J.A. Brito, M.L. Mendes, A.P. Nyczepir, and D.W. Dickson. 2007. Pathogenicity and reproductive potential of Meloidogyne mayaguensis and $M$. floridensis compared with three common Meloidogyne spp. Nematropica 37:21-31.

Chen, H., H. Chen, L. Hu, L. Wang, S. Wang, M.L. Wang, and X. Cheng. 2017. Genetic diversity and a population structure analysis of accessions in the Chinese cowpea [Vigna unguiculata (L.) Walp.] germplasm collection. Crop J. 5:363-372.

Das, S., P.R. Bhat, C. Sudhakar, J.D. Ehlers, S. Wanamaker, P.A. Roberts, X. Cui, and T.J. Close. 2008. Detection and validation of single feature polymorphisms in cowpea (Vigna unguiculata $\mathrm{L}$. Walp) using a soybean genome array. BMC Genomics 9:1-12.

de Melo, O. D., W. R. Maluf, R.J.S. Gonçalves, Á.C.G . Neto, L.A.A. Gomes, and R.C. Carvalho. 2011. Triagem de genótipos de hortaliças para resistência a Meloidogyne enterolobii. Pesqui. Agropecu. Bras. 46:829835.

Ehlers, J.D., W.C. Matthews, A.E. Hall, and P.A. Roberts. 2000. Inheritance of a broad-based form of root-knot nematode resistance in cowpea. Crop Sci. 40:611-618.

Elling, A.A. 2013. Major emerging problems with minor Meloidogyne species. Phytopathology 103:1092-1102.
Fatokun, C., G. Girma, M. Abberton, M. Gedil, N Unachukwu, O. Oyatomi, M. Yusuf, I. Rabbi, and O. Boukar. 2018. Genetic diversity and population structure of a mini-core subset from the world cowpea (Vigna unguiculata (L.) Walp.) germplasm collection. Sci. Rep. 8:1-10.

Fery, R.L. 2009. 'ZipperCream-GC', a largeseeded, cream-type southernpea with a green cotyledon phenotype. HortScience 44:14741475.

Fery, R.L. and P.D. Dukes. 1980. Inheritance of root-knot resistance in the cowpea (Vigna unguiculata (L.) Walp.). J. Amer. Soc. Hort. 105:671-674.

Gilmour, A.R., R. Thompson, and B.R. Cullis. 1995. Average information REML: An efficient algorithm for variance parameter estimation in linear mixed models. Biometrics 51:1440.

Guilherme, M.M.D., dos S.C. Willame, H.C.S Edgard, V.M . Marcus, A.F. Carolina, T.B. Leila, and L.M.S. Pedro. 2016. Screening melon genotypes for resistance to Meloidogyne enterolobii. Afr. J. Agr. Res. 11:2271-2276.

Harrison, H., D. Jackson, J. Thies, R. Fery, and J. Smith. 2014. US-1136, US-1137, and US-1138 cowpea lines for cover crop use. HortScience 49:364-366.

Helms, D., L. Panella, I.W. Buddenhagen, C.L. Tucker, K.W. Foster, and P.L. Gepts. 1991a. Registration of 'California Blackeye 46' cowpea. Crop Sci. 31:1703-1704.

Helms, D., L. Panella, I.W. Buddenhagen, C.L. Tucker, K.W. Foster, and P.L. Gepts. 1991b. Registration of 'California Blackeye 88'. Cowpea Crop Sci. 31:1703-1704.

Hussey, R.S. and K.R. Barker. 1973. A comparison of methods of collecting inocula of Meloidogyne spp., including a new technique. Plant Dis. Rep. 57:1025-1028.

Huynh, B.-L., T.J. Close, P.A. Roberts, Z. Hu, S. Wanamaker, M.R. Lucas, R. Chiulele, N. Cissé, A. David, S. Hearne, C. Fatokun, N.N. Diop, and J.D. Ehlers. 2013. Gene pools and the genetic architecture of domesticated cowpea. Plant Genome 6, doi: 10.3835/Plantgenome2013.03.0005.

Huynh, B., J.D. Ehlers, B.E. Huang, M. MuñozAmatriaín, S. Lonardi, J.R.P. Santos, A. Ndeve, B.J. Batieno, O. Boukar, N. Cisse, I. Drabo, C. Fatokun, F. Kusi, R.Y. Agyare, Y. Guo, I. Herniter, S. Lo, S.I. Wanamaker, S. Xu, T.J. Close, and P.A. Roberts. 2018. A multi-parent advanced generation inter-cross (MAGIC) 
population for genetic analysis and improvement of cowpea (Vigna unguiculata L. Walp.). Plant J. 93:1129-1142.

Huynh, B.-L., W.C. Matthews, J.D. Ehlers, M.R. Lucas, J.R.P. Santos, A. Ndeve, T.J. Close, and P.A. Roberts. 2016. A major QTL corresponding to the Rk locus for resistance to root-knot nematodes in cowpea (Vigna unguiculata L. Walp.). Theor. Appl. Genet. 129:87-95.

Jones, J.T., A. Haegeman, E.G.J. Danchin, H.S. Gaur, J. Helder, M.G.K. Jones, T. Kikuchi, R. Manzanilla-López, J.E. Palomares-Rius, W.M.L. Wesemael, and R.N. Perry. 2013. Top 10 plant-parasitic nematodes in molecular plant pathology. Mol. Plant Pathol. 14: 946-961.

Karuri, H.W., D. Olago, R. Neilson, E. Mararo, and J. Villinger. 2017. A survey of root knot nematodes and resistance to Meloidogyne incognita in sweet potato varieties from Kenyan fields. Crop Prot. 92:114-121.

Kiewnick, S., M. Dessimoz, and L. Franck. 2009. Effects of the Mi-1 and the $\mathrm{N}$ root-knot nematode-resistance gene on infection and reproduction of Meloidogyne enterolobii on tomato and pepper cultivars. J. Nematol. 41:134-139.

Langyintuo, A.S., J. Lowenberg-DeBoer, M. Faye, D. Lambert, G. Ibro, B. Moussa, A. Kergna, S. Kushwaha, S. Musa, and G. Ntoukam. 2003. Cowpea supply and demand in West and Central Africa. Fields Crops Res. 82:215-231.

Lonardi, S., M. Muñoz-Amatriaín, Q. Liang, S. Shu, S.I. Wanamaker, S. Lo, J. Tanskanen, A.H. Schulman, T. Zhu, M. Luo, H. Alhakami, R. Ounit, A.M. Hasan, J. Verdier, P.A. Roberts, J.R.P. Santos, A. Ndeve, J. Doležel, J. Vrána, S.A. Hokin, A.D. Farmer, S.B. Cannon, and T.J. Close. 2019. The genome of cowpea (Vigna unguiculata [L.] Walp.). Plant J. 98:767-782.

Martins, L.M.V., G.R. Xavier, F.W. Rangel, J.R.A. Ribeiro, M.C.P. Neves, L.B. Morgado, and N.G. Rumjanek. 2003. Contribution of biological nitrogen fixation to cowpea: A strategy for improving grain yield in the semi-arid region of Brazil. Biol. Fertil. Soils 38:333-339.

Matsui, T. and B.B. Singh. 2003. Root characteristics in cowpea related to drought tolerance at the seedling stage. Exp. Agr. 39:29-38.
McSorley, R., M. Ozores-Hampton, P.A. Stansly, and J.M. Conner. 1999. Nematode management, soil fertility, and yield in organic vegetable production. Nematropica 29:205-213.

Muñoz-Amatriaín, M., H. Mirebrahim, P. Xu, S.I. Wanamaker, M.C. Luo, and H. Alhakami, et al. 2017. Genome resources for climate-resilient cowpea, an essential crop for food security. Plant J. 89:1042-1054, doi: 10.1111/tpj.13404.

Muñoz-Amatriaín, M., S. Lo, I.A. Herniter, O. Boukar, and C. Fatokun. 2021. The UCR Minicore: a valuable resource for cowpea research and breeding. bioRxiv 1-18, doi: 10.1101/2021.02.09.430326.

Ndeve, A.D., W.C. Matthews, J.R. Santos, B.L. Huynh, and P.A. Roberts. 2018. Broad-based root-knot nematode resistance identified in cowpea gene-pool two. J. Nematol. 50(4):545.

Ripley, B., B. Venables, D. Bates, K. Hornik, A. Gebhardt, and D. Firth. 2020. Package MASS. CRAN, New York, NY.

Roberts, P.A., W.C. Matthews, and J.D. Ehlers. 1996. New resistance to virulent root-knot nematodes linked to the $R k$ locus of cowpea. Crop Sci. 36:889-894.

Rodrigues, A. C., J. A. G. Silveira, A. Bonifacio, and M.V.B. Figueiredo. 2013. Metabolism of nitrogen and carbon: Optimization of biological nitrogen fixation and cowpea development. Soil Biol. Biochem. 67:226-234.

Samireddypalle, A., O. Boukar, E. Grings, C.A. Fatokun, P. Kodukula, R. Devulapalli, I. Okike, and M. Blümmel. 2017. Cowpea and groundnut haulms fodder trading and its lessons for multidimensional cowpea improvement for mixed crop livestock systems in West Africa. Front. Plant Sci. 8:30.

Santos, D., I. Abrantes, and C. Maleita. 2019. The quarantine root-knot nematode Meloidogyne enterolobii: A potential threat to Portugal and Europe. Plant Pathol. 68:1607-1615.

Singh, B.B. 2002. Recent genetic studies in cowpea, p. 3-13. In: C.A. Fatokun, S.A. Tarawali, B.B. Singh, P.M. Kormawa, and M. Tamo (eds.). Challenges and opportunities for enhancing sustainable cowpea production. IITA, Ibadan, Nigeria.

Singh, B.B. 2020. Cowpea: The food legume of the 21 st century. Wiley.
Singh, S.K., M. Hodda, and G.J. Ash. 2013. Plantparasitic nematodes of potential phytosanitary importance, their main hosts and reported yield losses. Bull. OEPP 43:334-374.

Singh, R.J. and P.P. Jauhar. 2005. Genetic resources, chromosome engineering, and crop improvement. 1st ed. CRC Press, Boca Raton, FL.

Swanson, T.A. and S.D. Van Gundy. 1984. Cowpea resistance to root knot caused by Meloidogyne incognita and M. javanica. Plant Dis. 68:961.

Taylor, A.L. 1967. Introduction to research on plant nematology: An FAO guide to the study and control of plant-parasitic nematodes. Food and Agricultural Organization of the United Nations, Rome, Italy.

Taylor, A.L. and J.N. Sasser. 1978. Biology, identification and control of root-knot nematodes. North Carolina State University Graphics, 111. $<$ http://citeseerx.ist.psu.edu/viewdoc/download? doi $=10.1 .1 .471 .129 \&$ rep $=$ rep1\&type $=p d f>$.

Tigano, M., K. de Siqueira, P. CastagnoneSereno, K. Mulet, P. Queiroz, M. dos Santos, C. Teixeira, M. Almeida, J. Silva, and R. Carneiro. 2010. Genetic diversity of the root-knot nematode Meloidogyne enterolobii and development of a SCAR marker for this guava-damaging species. Plant Pathol. 59: 1054-1061.

Timko, M.P., J.D. Ehlers, and P.A. Roberts. 2007. Cowpea, p. 49-67. In: Pulses, sugar and tuber crops. Springer, Berlin, Germany.

Timko, M.P. and B.B. Singh. 2008. Cowpea, a multifunctional legume, p. 227-258. In: Genomics of tropical crop plants. Springer, New York, NY.

Westerich, J.N., J.M.O. Rosa, and S.R.S. Wilcken. 2011. Estudo comparativo da biologia de Meloidogyne enterolobii (= M. mayaguensis) e Meloidogyne javanica em tomateiros com gene mi. Summa Phytopathol. 37:35-41.

Zambon, F.T., T.A. Eluri, C.A. Chase, and X. Zhao. 2013. Weed and root-knot nematode management in an organically managed high tunnel, p. 161-164. In: Proceedings of the Florida State Horticultural Society. Florida State Horticultural Society, Goldenrod, FL. 
A

Meloidogyne incognita

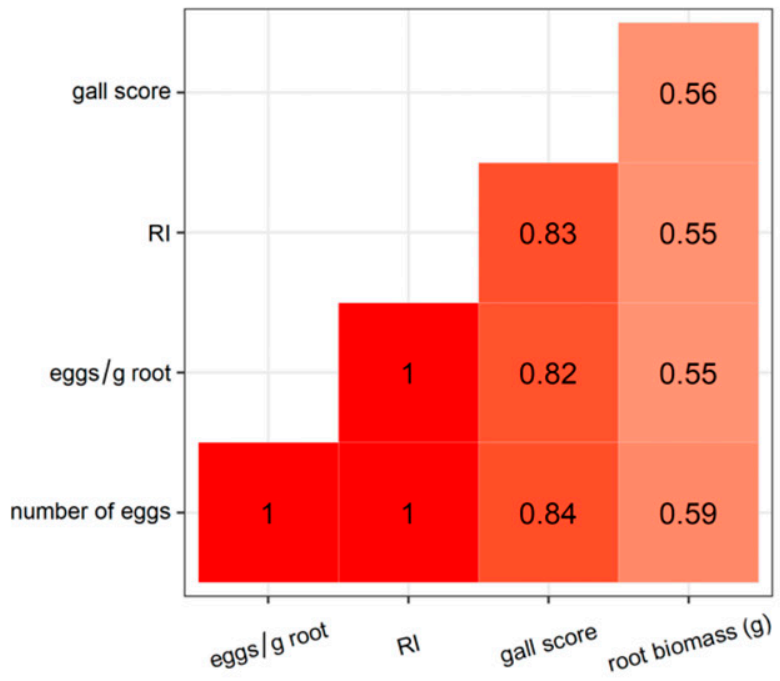

\section{C eggs/g root}

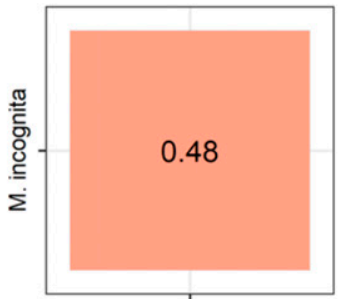

M. enterolobii
RI

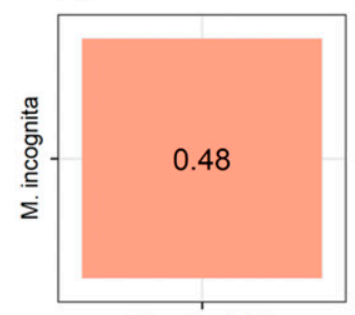

M. enterolobii
B
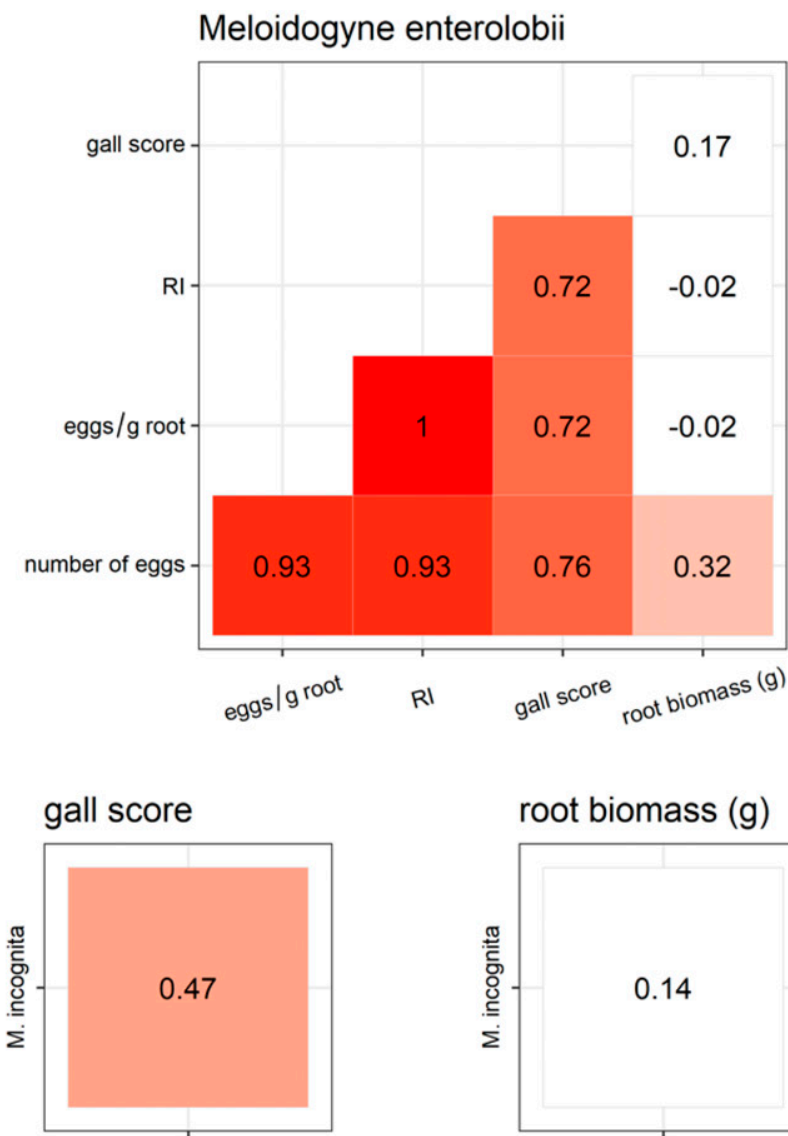

M. enterolobii root biomass (g)

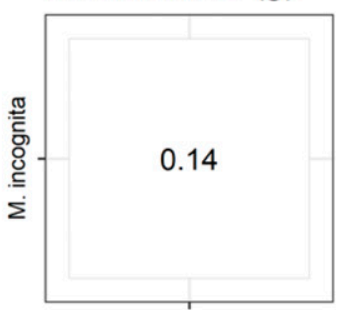

M. enterolobii

\section{Corr}

$\begin{array}{lllll}-1.0 & -0.5 & 0.0 & 0.5 & 1.0\end{array}$

Supplemental Fig. 1. Pearson correlations among traits measured in (A) 72 cowpea genotypes infected with Meloidogyne incognita and (B) 67 cowpea genotypes infected with M. enterolobii. (C) Pearson correlations among predicted values for four traits measured in 63 cowpea genotypes infected with M. incognita and M. enterolobii. Traits: gall_score $=$ gall score; eggs $=$ number of eggs; eggs $/ \mathrm{g} \mathrm{rt}=$ number of eggs per gram of root; $\mathrm{RI}=$ reproduction index; root_biomass $=$ root fresh weight. Correlation coefficients in white are not significant at $P<0.05$, whereas colored codes indicate a significant correlation at $P<0.05$. 